End Dump Bodies for Commercial Vehicles

By Ross Babcock. M.E.

A $\mathrm{S}$ divided as are opinions on the op$A_{\text {erative cost of commercial vehicles, }}$ engineers are of one mind that truck efficiency demands the reduction of idle time to the minir maximum efficiency with any piece of machinery requires its operation at as nea to full capacity as is possible, and the limination of work or movement that ot strictly useful; and the motor truck is no exception to the general rule. It costs very nearly as much to operate a truck light as it does to operate it loaded, and where it is not possible with the aid of removable bodies, for instance, to reduce the ratio of time spent in idle running to time spent in performing useful work, other means must be adopted. Otherwise it is altogether likely that the vearly balance will be on the wrong side of the owner's books.

Until comparatively recently little heed of specialized body designs has been taken by commercial vehicle builders, though within the past twelvemonth thi feature has come in for its just measure of attention. One reason for the noteworthy change of front on the part of manufacturers very likely is due to a general awakening to the fact that if outputs are to be disposed of, the maker must not only help the purchaser by showing him how to use existing designs with profit to himself, but in addition he must suggest new uses for his products or adapt them to uses heretofore served only by horse-drawn vehicles.

In this respect, it is interesting to note that the end dumping body, either manually or mechanically operated, slowly but surely is assuming the place of importance it undoubtedly deserves: There are abundant reasons why this should be so. Given sand or coal or broken ston to handle, for instance, acute sight is not needed to make plain that antiquated unloading methods-shovels and the muscular power of a "sang"-scarcely are com" modernness expressed by the vehicle itself. Such methods necessitate that virtually all the time saved by he motor truck in making the haul quick$\mathrm{y}$ be sacrificed in unloading. Hence, it is entirely logical that some means of making up the deficiency be sought for, and the dumping body truck represents that means. Already there are a score or more of makers who specialize in the construction of such apparatus, and if the present tendency can be taken as a criterion, the ranks of those manufacturers without doubt will be materially swelled in th not far distant future.

There are four general types of dumping bodies, and they are nearly all of the up-ending variety. Side dumping bodies are not much used, probably because it is so much easier to maneuver a motor truck than it is to maneuver a horse-drawn one. Seldom is space so restricted that it is Seldom is space so restricted that it is
impossible to back the truck into position. In designing these dumping bodies, the tremendous power of the screw is understood and has been very liberally made use of. Hence, the screw-operated mechanism forms one group by itself. The other
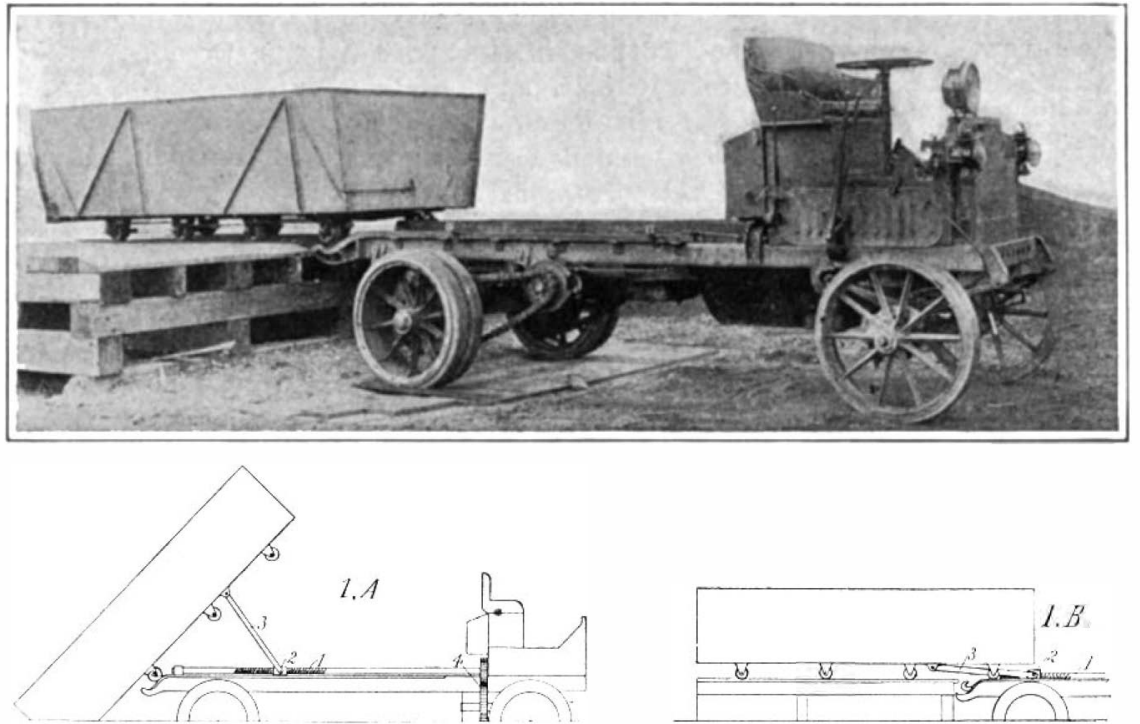

Figs. 1, 1A and 1B.-Motor truck with dumping and "demountable" body.

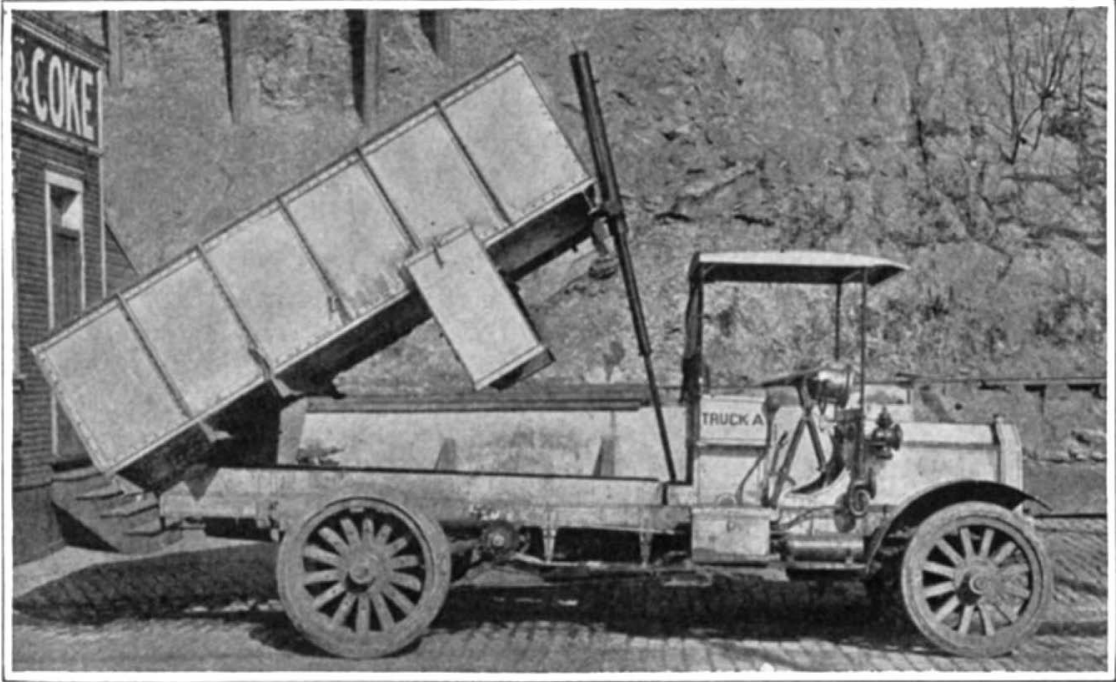

Fig. 2.-Dumping body elevated by a double telescoping screw.
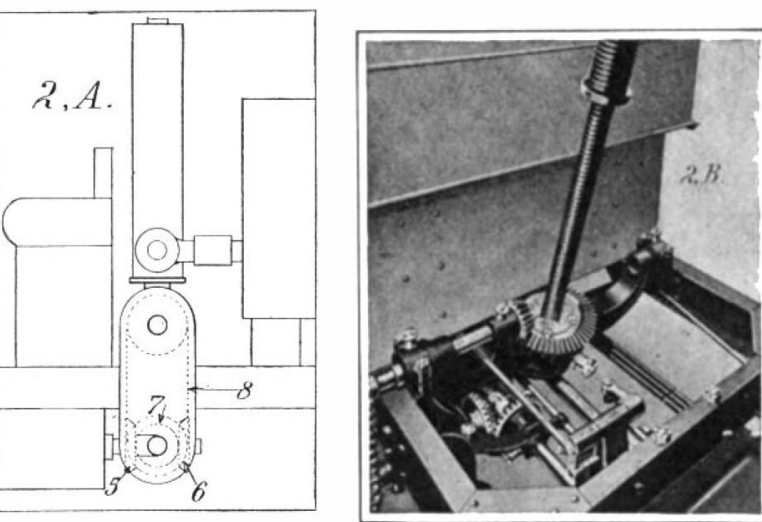

i

Figs. 2A and 2B.-Telescoping screw details. Fig. 3A.-Plain screw elevator

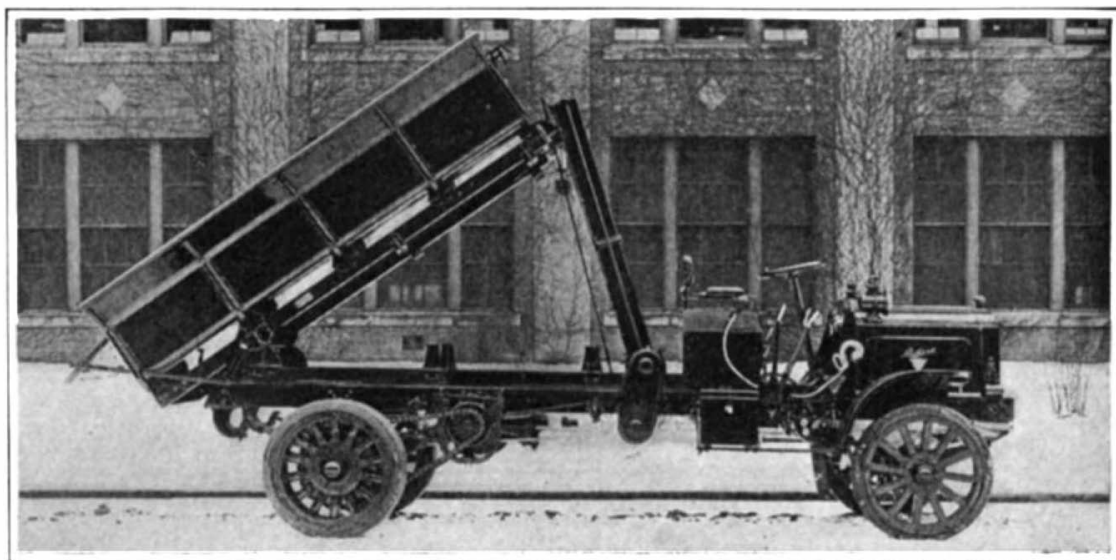

Fig. 3.-Dumping body elevated by a power-driven plain screw. three groups may be broadly classified into (2) those that employ some sort of rack and pinion mechanism, (3) those that are chain hoisted, and (4) those that are hydraulically operated.

In the first group, the vehicle shown in Fig. 1, and diagrammatically in Figs. $1 A$ and $1 B$, is interesting, for it not only provides a means of dumping the body with the power of the engine, but the body is "demountable" as well. For operation, it depends upon a longitudinal screw 1 driven through a pair of gears 4 by the engine. A nut 2 on the screw is hinged to an arm 3 which is permanently attached to the body. The body is mounted on rollers. As it is forced backward by the screw, the first pair of rollers drops into the curved end of the track on the chassis, thus forming a bearing on which the body tilts. When the body is to be dismounted, the truck is backed up to a platform of the proper height and then, instead of dropping into the curved ends of the track, the first pair of rollers passes upon the platform and the body contines straight platerm in is clear of the chass, when the arm 3 is uncoupled from the screw at the nut 2. To return the body to its normal position, the direction of rotation of the screw is reversed by an idler pinion which is brought into action by means of lever conveniently placed at the driver's right hand.

In Figs. 2, $2 A$ and $2 B$ an altogether different and more popular arrangement of the screw and nut principle is depicted. In this case the screw is vertically mounted on a swiveling joint and driven from bevel gears and chain from the propeller shaft. The screw itself is virtually a double screw, or one screw telescoping into another. Thus, when the body is down, the height of the screw is only slightly greater than the height of the body. The double screw is operated from a pair of bevel wheels 5 and 6 , mounted on a shaft and arranged so that either may be clutched by means of a lever at the driver's seat. Engagement of the bevel 5 therefore causes the sprocket wheel 7 to turn in one direction, the movement being transmitted to the screw through the intermediary of a chain 8 and another pair of mediary of a chain 8 and another pair of
bevels, and thus to hoist the body. Enbevels, and thus to hoist the body. En-
gaging the other bevel 6 causes the chain gaging the other bevel 6 causes the chain to run in the opposite direction, thus bringing the body down aga 6 are mounted on which the bevels 5 and 6 are is driven from the another pair of bevel gears In operation, the inner screw first rotates within the outer one, raising the body half way, when a stop causes the outer screw to rotate within its casing, raising the body the rest of the way.

The arrangement shown in Figs. 3 and $3 A$ is considerably simpler, though it has the disadvantage that when the body is lowered the screw projects above the body quite a distance. It is thoroughly protected, however, and there can be little objection to it unless the vehicle is to be used where the head-room is very restricted. In this case the elevating screw 9 is driven by a short inclosed chain 10 from a transverse shaft which is driven by a pair of inclosed bevels on the clutch shaft. Engaging either bevel serves to rotate the screw in either direction, thus causing the (Concluded on page 382.)

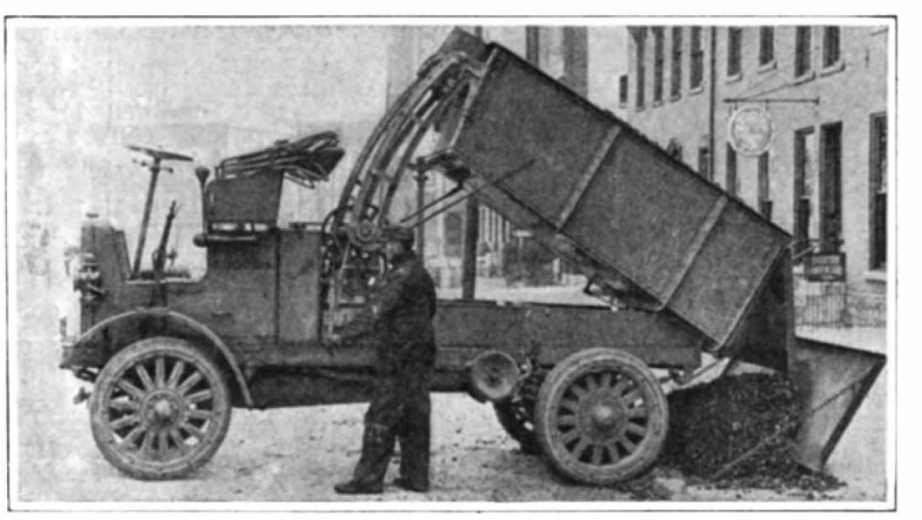

Figs. 4 and 4 A.- One of the simplest types; a hand-operated pinion and curved rack.

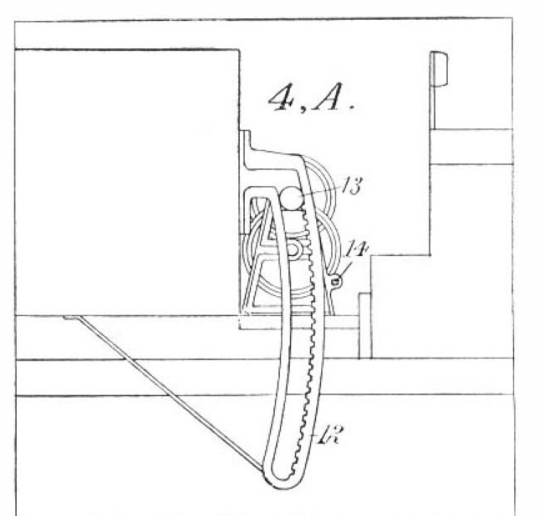

Fig. 5.-Plain rack and pinion and chain for drawing the body back,

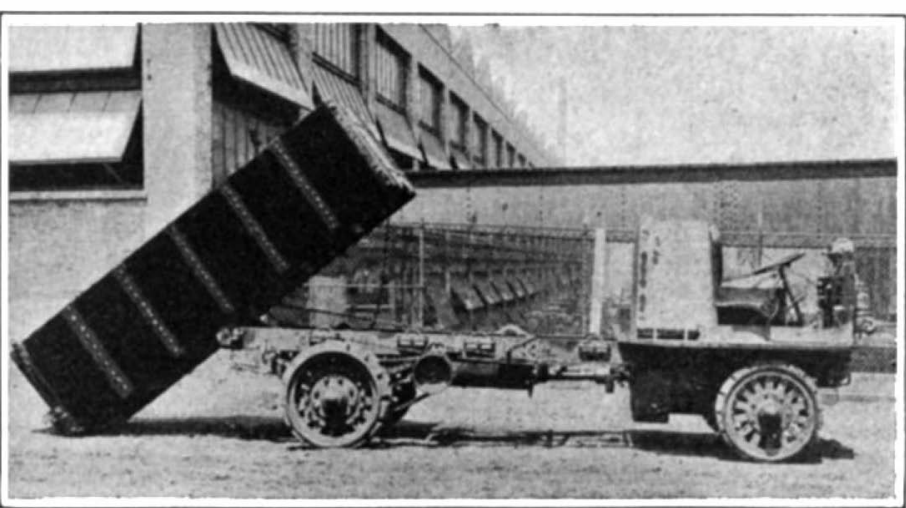

HICLES 


\section{The Motor-driven Commercial Vehicle}

This department is devoted to the interests of present and prospective owners of motor trucks and delivery wagons. The Editor will endeavor to answer any questions relating to mechanical features, operation and management of commercial motor vehicles.

End Dump Bodies for Commercial Vehicles

roucluded from page 379

nut 11 to travel either up or down, raising or lowering the body.

Passing from the screw and nut operating mechanism, the rack and pinion mechanism illustrated in Figs. 4 and $4 A$ probably is the simplest of all those illustrated. It is so simple in fact that it scarcely requires explanation. The curved rack 12 is attached to the body and operated by the pinion 13 , which in turn is operated through a train of gears givin the required reduction. A hand crank connected at 14 serves to operate the train of gears and the muscle of the driver is the elevating energy.

In Figs. 5 and $5 A$ the rack and pinion principle also is employed, though the method of application is quite different The rack 15 is mounted on the body. Rotation of the pinion 16 by means of a crank attached at 17 serves to move the body backiner until it over-balances and tips itself. w it back into position, it chail 18 winding on a drum 19 , which is operated through a train of gear wheels set in motion with a crank attached at 20 is employed.

With the aid of a special "fifth wheel" arrangement the body illustrated in Fig. 6 has been made particularly adaptable for use in constricted areas where it is impossible to back the vehicle into position for unloading. The body is swung around by hand (the "fifth wheel" is mounted on rollers) and dumped manually through combined chain hoisting and movable fulcrum arrangement, shown diagrammatically in Fig. $6 \mathrm{~A}$. In operation, the chain 21, which is attached to the arm 22 is wound up on a drum 23 through a wound un on a drum 23 through a trai tached tached at 24 The arm 22 has a roller at its lower end which travels on a meta track, thus reducing friction to the minimum. The body returns to its norma position by gravity.

A somewhat similar arrangement is shown in Figs. 7 and $7 A$, though the method of application of the movable fulcrum is quite different. The arm 25 is pivoted is quite different. The arm 25 is pivoted
to the body and travels on a track on the chassis, the chain 26 being attached at its lower end, and wound up on a drum $2 \gamma$ operated through a train of gear wheels by a hand crank attached at 28. Thus, winding up the chain draws the arm 25 to the rear and hoists the body, which re turns to its lowered position by gravity turns
alone.

Operating on the rolling fulcrum principle, which permits the application of the greatest power at first, with a gradua diminishing of power as the load is raised
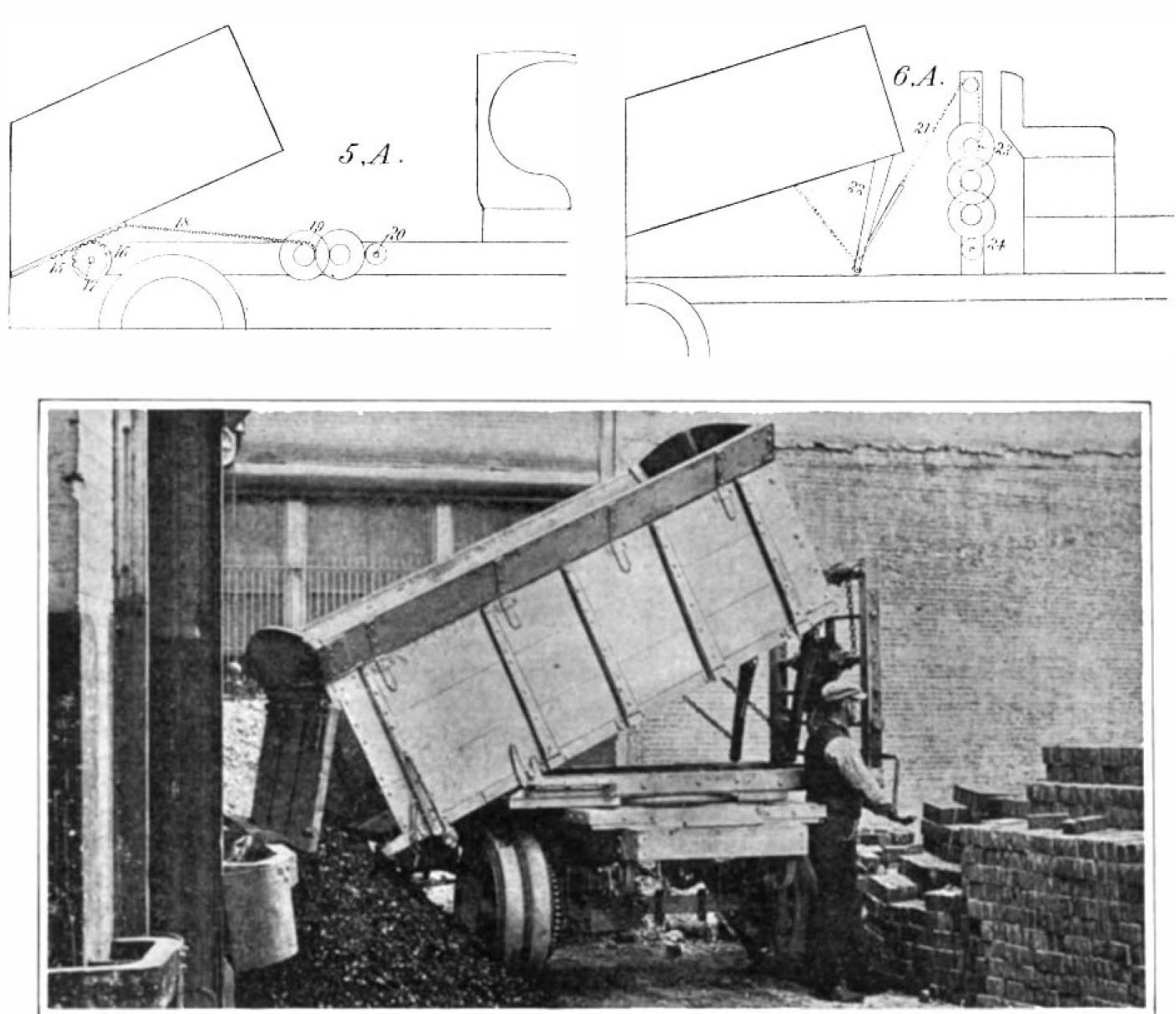

Fig. 5A.-Details of Fig. 5. Figs. 6 and 6A.-Swiveling dumping body.



Fig. 7.-Elevating gear employing a sliding fulcrum.
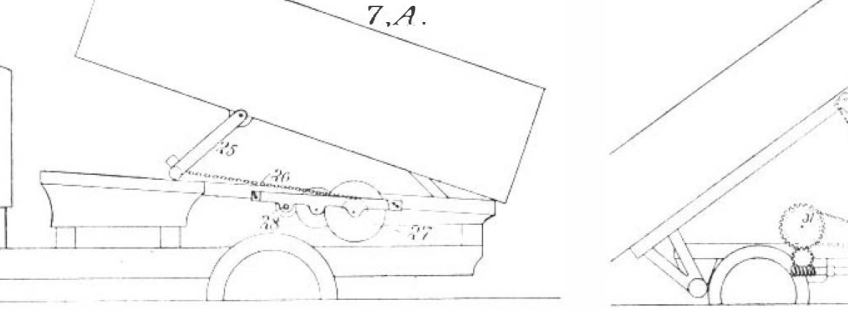

Fig. 7A.-Details of sliding fulcrum. Fig. 8A.-The rolling fulcrum into position and less effort is required to raise it, the arrangement depicted in $\mathrm{Firs}$. 8 and $S A$ is unusual and is different from any of the others. The arm 29 is pivoted to the body and operated by the chain 30 running over a chain wheel 31 , which is worm-driven from a shaft 32 , driven in turn by spur gears from the propeller shaft. The body is hauled down by reversing the bodis is he the shaft 32 by means of an idler gear controlled by the driver from- his seat.

The mechanism governing the hydraulic hoist shown in Figs. 9 and $9 A$ is operated from a countershaft extended at the front end of the gear set. On this shaft are mounted respectively a chain sprocket and a driving clutch A lever permits the clutch to slide along the shaft and engage with the sprocket. Alongside the gear set there is a countershaft mounted in ballbearings from which a rotary oil pump is driven. The pump is connected to the cylinder of the hydraulic ram by means of a suction pipe 33 leading into the top of the cylinder. The oil under pressure forces the piston 34 up until the top of the stroke is reached, at which point a strike valve opens three ports in the piston, allowing the oil to escape freely into the top portion, thereby holding the body at rest. The actual lifting of the body is accomplished through the intermediary of a flexible steel cable 35 passing over two sheaves 36 and under a central third sheave $3 \%$ Thus, for a given lift of the piston the body is raised twice the height. The third sheave acts as a compensating device equalizing the lifting force on both sides of the body. The whole mechanism is firmly braced to the chassis, but in such a manner that it can be detached as a complete unit without disturbing the truck chassis itself.

Horse Trucking Costs Estimated by a Team Owners' Association OE of the problems which the motor face when he comes to compare motor vehicle with horse transportation costs is the lack of any definite figures on the cost of using horses.

Members of the Team Owners' Association of Boston, which is made up of a hundred or more of the leading men engaged in the trucking business of that city, recently became involved in a discity, recently became involver in a discussion over this question, which resulted in the employ ant to investigate the subject, and his report was read before a meeting of the association. This report is in part as folows

"To start with, there are 365 or 366 (Concluded on page 384.)



Fig. 8.-The rolling fulcrum varies the leverage as required.
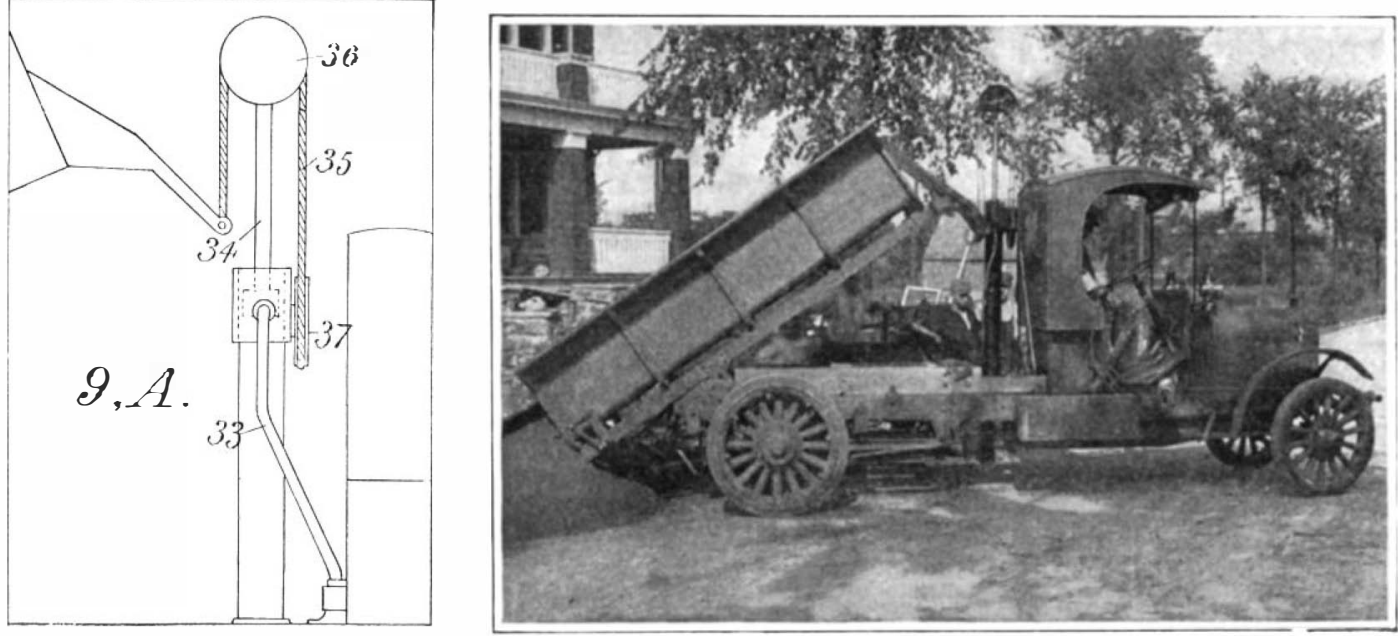

Figs. 9A and 9.-Raising a car body by hydraulic pressure on a piston 